\title{
Multiple Skin Bridging for No-Touch Saphenous-Vein Grafts Harvesting Can Reduce Wound Morbidity
}

\author{
Kang Zhou, MD, Xiaoke Qi, MD, Shijie Wei, MD, Xinmin Zhou, MD, PhD, Yuan Zhao, MD, PhD \\ Department of Cardiovascular Surgery, The Second Xiangya Hospital, Central South University, Changsha, China
}

\section{ABSTRACT}

Background: Reducing the leg wound morbidity is crucial for the patients undergoing coronary artery bypass grafting (CABG) with great saphenous vein (SV) grafts harvested by no-touch (NT) technique. This study was to summarize the experience of skin bridging technique for reducing wound morbidity and the influence of it on one-year bypass graft patency.

Methods: According to skin bridging or not, harvesting times, graft length, number of bleeding branches, postoperative subjective perception assessment scale (ASEPSIS) scores and one-year patency rate were analyzed.

Results: From June 2018 to February 2019, 60 patients underwent CABG with SV grafts either with open-incision NT or skin bridging NT (30 in each group). There were no significant differences in age $(71.4 \pm 5.1$ years vs. $68.9 \pm$ 5.5 years $)$ or graft length $(23.3 \pm 1.1 \mathrm{~cm}$ vs. $23.9 \pm 1.3 \mathrm{~cm})$ between the two groups. The bridging/NT group had a significantly longer harvest time $(38.5 \pm 4.9 \mathrm{~min}$ vs. $18.5 \pm 2.6$ min; $\mathrm{P}<0.001)$ and a significantly greater number of bleeding branches $(1.9 \pm 1.2$ vs. $0.8 \pm 0.8 ; \mathrm{P}<0.001)$ than the open $\mathrm{NT}$ group. The open NT group had a significantly higher ASEPSIS score $(23.8 \pm 2.0$ vs. $15.7 \pm 2.6 ; \mathrm{P}<0.001)$. There was no significant difference in patency rate at one-year follow up.

Conclusion: Obtaining the SV by the combined NT/discontinuous skin bridging technique is a satisfactory method for patients underwent CABG. This method has important clinical significance in reducing wound morbidity in the harvest of NT grafts.

\section{INTRODUCTION}

Coronary-artery bypass (CAB) surgery is still a reliable method for effectively treating coronary heart disease (CHD). The choice of grafts has a great impact on the long-term patency rate after coronary-artery bypass grafting (CABG). Both European and American guidelines for the treatment

Received April 8, 2021; received in revised form April 18, 2021; accepted April 19, 2021.

Correspondence: Yuan Zhao, Telephone +86-731-85295102, Fax +86-73185292133 (e-mail:drzbaoyuan@csu.edu.cn). of CHD explicitly recommend the use of arterial vessels as a source of grafts wherever possible [Windecker 2014; Patel 2017]. However, in some cases, such as elderly patients or in patients needing long grafts, saphenous-vein (SV) grafts often are required. Generally speaking, vein grafts have the advantages of easy access, large diameter, and easy anastomosis. However, past experience has shown that the short- and long-term patency rates of SV grafts are significantly lower than those of arterial grafts [McKavanagh 2017]. With the introduction of no-touch (NT) technique to obtain SV grafts in clinical practice more than 20 years ago [Souza 1996], an increasing number of studies have indicated that NT access to SV grafts significantly can improve the patency of these grafts, and some even report that patency of NT SV grafts can be as high as those of internal mammary-artery grafts [Souza 2002; Souza 2006; Janiec 2018]. However, in clinical practice, it is universally agreed that NT technique damages the soft tissue of the leg too much, often resulting in poor wound healing and even infection [Souza 2016]. People with diabetes therefore are often excluded from this technique. There already are some commonly used minimally invasive methods to reduce leg wound morbidity, such as the discontinuous skin bridging technique [Black 2002]. In this study, we aimed to verify the feasibility and reliability of this method that combines the advantages of discontinuous skin bridging and the NT technique to obtain SV grafts, with the hope of improving the long-term patency of SV grafts, as well as reducing damage to patients' leg wounds.

\section{METHODS}

Study design: Consecutive patients $>60$ years old with multivessel coronary-artery disease (CAD) in the same surgical treatment group underwent isolated CABG using both the left internal mammary artery (LIMA) and the SV as graft vessels. These blood vessels randomly were obtained using two NT methods. For the first group, the open NT group, SV grafts were obtained by the NT method in a full openskin incision. For the other group, the bridging/NT group, we used the discontinuous skin bridging technique: The skin intermittently was cut, and the vein grafts were harvested via the NT technique. The vein graft acquisition site was usually the patient's left leg, unless this side was not suitable for harvesting. The acquisition range was from the ankle to below the knee joint. All of the SV grafts were obtained by the same experienced attending physician. The exclusion 
criteria were patient age $<60$ years, emergency $\mathrm{CAB}$ surgery, combined valve or aortic surgery, saphenous varicose veins, and ventricular aneurysm. All patients underwent off-pump $\mathrm{CAB}$ surgery under a median incision. The LIMA was anastomosed with the anterior descending branch, the SV graft was anastomosed with the root of the aorta, and the graft configuration strategy sequentially was anastomosed with other target vessels.

Coronary computed-tomography angiograms (CTAs) routinely were completed before discharge from the hospital to test graft patency; otherwise, the case was excluded. We used 64-slice dual-flush multi-detector computed-tomography (MDCT; GE Healthcare, Chicago, IL, USA) angiography to determine graft patency from morphological characteristics. Infection assessment of leg wound were scored by the postoperative wound recovery score (ASEPSIS) tool [Wilson 1986] on the first 5 postoperative days. Severity of impaired wound healing was indicated by the total score $0-40$ : from satisfactory healing to different degrees of infection, the higher the score, the more serious the infection. Patient satisfaction evaluation simultaneously was recorded with wound assessment, using a self-reporting technique, rated the satisfaction on a numeric scale ranging from 0 (extremely dissatisfied) to 10 (very satisfied).

The study protocol was approved by the Ethics Committee of the Second Xiangya Hospital of Central South University, Changsha, China. Preoperative written informed consent was provided by the patients' relatives.

Surgical techniques: All CABG operations were performed with off-pump CABG through median stern incision. All of the vein grafts were anastomosed by sequentially bypassing into the three non-left anterior descending (LAD) arteries on the left side of the heart. First, we used a continuous double-arm Prolene 6-0 suture for proximal-bypass anastomosis of the vein graft, which was naturally expanded by aortic pressure.

We conducted open NT harvesting of the SV using the method reported in the literature [Inaba 2019] (Figure 1A). (Figure 1) The specific method of NT combined with skin bridging for harvesting the SV graft was as follows: We longitudinally cut the skin $3.0-4.0 \mathrm{~cm}$ from about $2 \mathrm{~cm}$ above the ankle, above the medial malleolus. After finding the trunk of the SV, we used a blunt scissor to separate a $4.0-6.0 \mathrm{~cm}$ length of the outer membrane of the SV to the proximal end, and then we pulled the hook to help reveal a $2.0-3.0 \mathrm{~cm}$ subcutaneous tunnel. Using a scissor head that was passed through the tunnel as a guide, we cut a longitudinal incision of about $5.0-6.0 \mathrm{~cm}$ intermittently along the great SV, leaving some skin gaps until an SV graft of sufficient length was obtained. The result was 3-5 skin incisions 4.0-6.0 cm in length between $2.0-3.0 \mathrm{~cm}$ long skin gaps in the leg (Figure 1B). When freeing the SV, we kept about $5.0 \mathrm{~mm}$ of soft tissue on both sides (including the companion nerve) to ensure sufficient thickness of the blood vessel adventitia. When encountering a large branch, we tried to stay as close to the main trunk as possible, and we clamped it together with the surrounding soft tissue. The free SV was pulled with a soft rubber band throughout the process, preventing any metal surgical instruments from touching the vein itself. The free SV with pedicle was removed $5 \mathrm{~min}$ after heparinization. After a short immersion in heparin saline containing papaverine, we anastomosed the distal end with the aortic root and clamped the other end to put it under the pressure of the aortic root's spontaneous expansion, without using a syringe to expand the lumen. After LIMA anastomosis was completed, we successively anastomosed the vein grafts with the target vessels of each coronary-artery stenosis branch. Anastomosis was started from the diagonal branch, proceeding to the obtuse marginal branch and the left ventricular posterior or posterior descending branch of the left ventricle. The length of the entire graft was kept slightly longer than the anatomical distance between the revascularized arterial points in order to avoid anastomotic tension. We used a Prolene 7-0 suture for lateral anastomosis between the graft and target vessels. The leg incision was bandaged under pressure and elastic bandages; the pressure was released on the first day after surgery. A small silicone drainage tube was placed in the incision and removed two or three days post-surgery. If there was no obvious drainage on the first postoperative day, aspirin and ticagrelor were routinely prescribed to all of the patients that day. If no bleeding-related complications occurred during the follow-up period, the dual antiplatelet was continued for one year.

Statistical analysis: All of the statistical analyses were performed with SPSS software version 24.0 (IBM Corp., Armonk, NY, USA). The enumerated data are presented as frequencies and percentages and were compared using the chi-square test or Fisher's exact test. The measurement data are expressed as means \pm standard deviation (SD) and were compared using an unpaired t-test. Statistical significance was accepted when the $P$-value was $<0.05$.

\section{RESULTS}

Patient characteristics and intraoperative data: We studied a total of 60 patients, including patients with diabetes mellitus. (Table 1) Baseline clinical characteristics of both groups are shown in Table 1 . The average age at surgery in the open NT group and in the bridging/NT group were $68.9 \pm 5.5$ years and $71.4 \pm 5.1$ years, respectively. The average graft length was $22.5 \pm 3.5 \mathrm{~cm}$ in the bridging/NT group and 24.5 $\pm 2.7 \mathrm{~cm}$ in the open NT group. The average harvest time was $40.7 \pm 10.4 \mathrm{~min}$ in the bridging/NT group and $15.8 \pm 7.6$ min in the open NT group $(P<0.001)$. (Table 2$)$ The number of bleeding branches was $3.2 \pm 1.5$ in the bridging/NT group and $1.4 \pm 0.6$ in the open NT group (Figure 2A). (Figure 2) Other intraoperative and postoperative data are listed in Table 2. No graft stenosis or obstruction was found during CTA at the time of discharge. However, one-year follow up revealed that six grafts had failed in the open NT group (108/114), and three had failed in the bridging/NT group (113/116) but there was no significant difference in occlusion rates at the 12-month CTA follow up.

Complications and adverse events: All patients survived one year post-surgery. No leg wound infections occurred in either group during follow up. Postoperative wound recovery score (ASEPSIS) was significantly better in the bridging/ 
NT group $(15.7 \pm 1.8)$ than in the open NT group $(23.8 \pm$ 2.0; Figure 2B). In the open NT group, necrosis of the skin and skin margin of the lower-limb incision occurred in some patients, but without infection (4 of 24; Figure 3A); it did not occur in the bridging/NT group. (Figure 3) There was no need for negative-pressure wound therapy or intravenous antibiotics for any leg wound of any patient, and both groups had good prognoses at the post-one-year follow up (Figure $3 \mathrm{~B})$. The 30-day mortality rate was zero in both the groups. In addition, there were no adverse events during the CTA follow up at 12 months.

\section{DISSCUSION}

At present, although the long-term patency of arterial grafts is better than that of venous grafts, it is recognized that vein grafts still account for the vast majority used in some elderly patients [Samano 2018]. In the 1990s, Souza et al. proposed the "no-touch" (NT) method for obtaining vein grafts [Souza 1996] and carried out a series of basic and clinical studies, confirming that this method could maintain the intimal integrity of the grafts in order to maintain a good long-term patency rate, among other significant advantages [Johansson 2015; Samano 2020]. According to a clinical follow-up study, Souza's team conducted for nearly 16 years, vein grafts obtained by NT can achieve a long-term patency rate of about 83\% [Samano 2015]. In some special cases, NT SV grafts can even replace LIMA grafts and obtain a comparable long-term patency rate [Samano 2017]. In view of a series of excellent performances on the long-term patency rate of vein
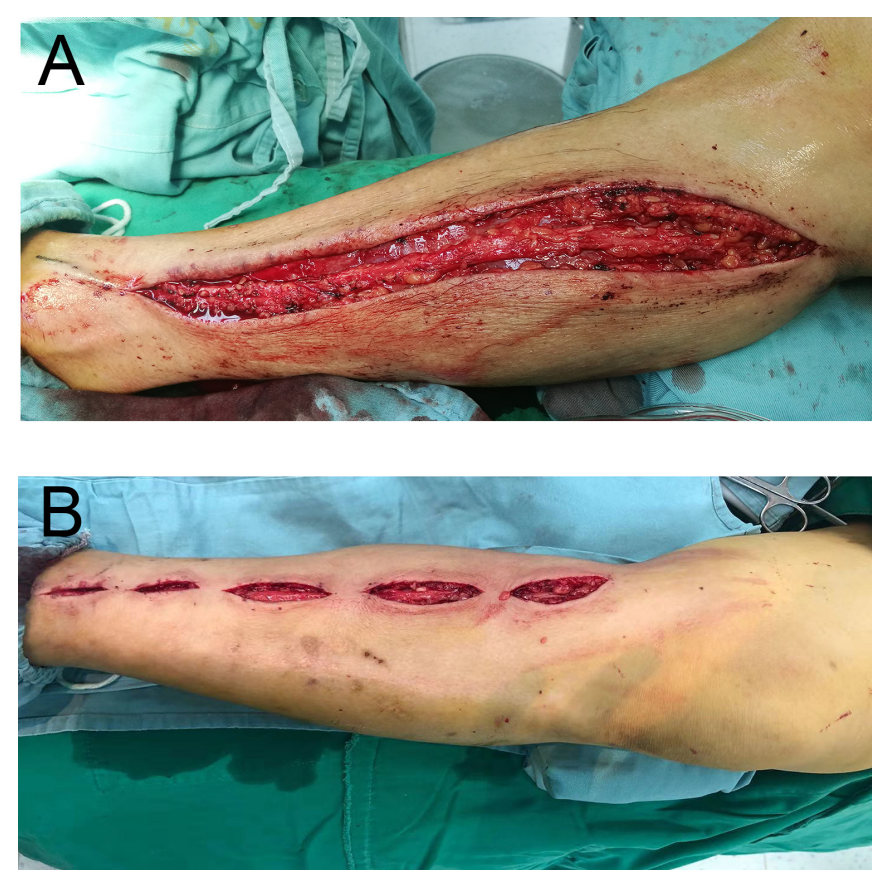

Figure 1. Intraoperative harvesting examples of (A) full open NT SV graft and (B) skin bridging/NT SV graft. grafts obtained by the NT technique, the latest guidelines in Europe and the United States have recommended that the NT method of obtaining vein grafts be classified as type IIa [Neumann 2019]. However, this technique quite often damages the soft tissues around the veins, in which case poor healing and even infection of leg wounds easily happen. Therefore, a series of clinical studies, including that by Souza himself, have often excluded patients with diabetes. The problem of excessive tissue damage also is the main reason that a considerable number of surgeons have reservations about the NT technique. Souza recently published the results of a multi-center randomized controlled trial, showing that the incidence of recent wound infections with vein grafts obtained by NT was significantly higher than that was the case for traditional methods [Deb 2019].

Obtaining vein grafts through minimally invasive methods to reduce leg complications always has been widely accepted. At present, the commonly used methods include endoscopy
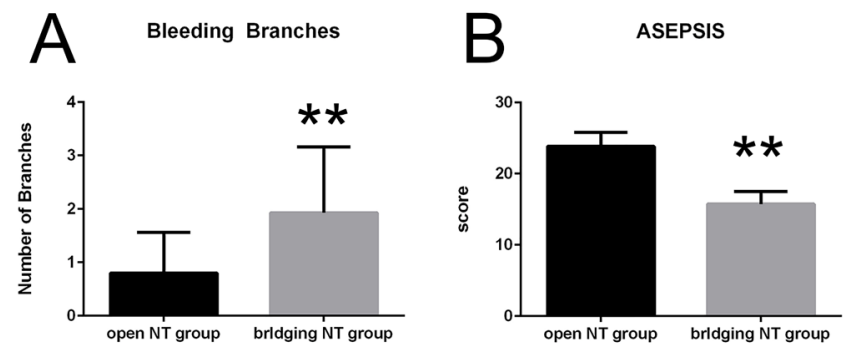

Figure 2. Schematic of (A) number of bleeding branches and (B) ASEPSIS scores in both groups after harvesting of the NT SV graft during the operation. ${ }^{*} P P<0.001$.
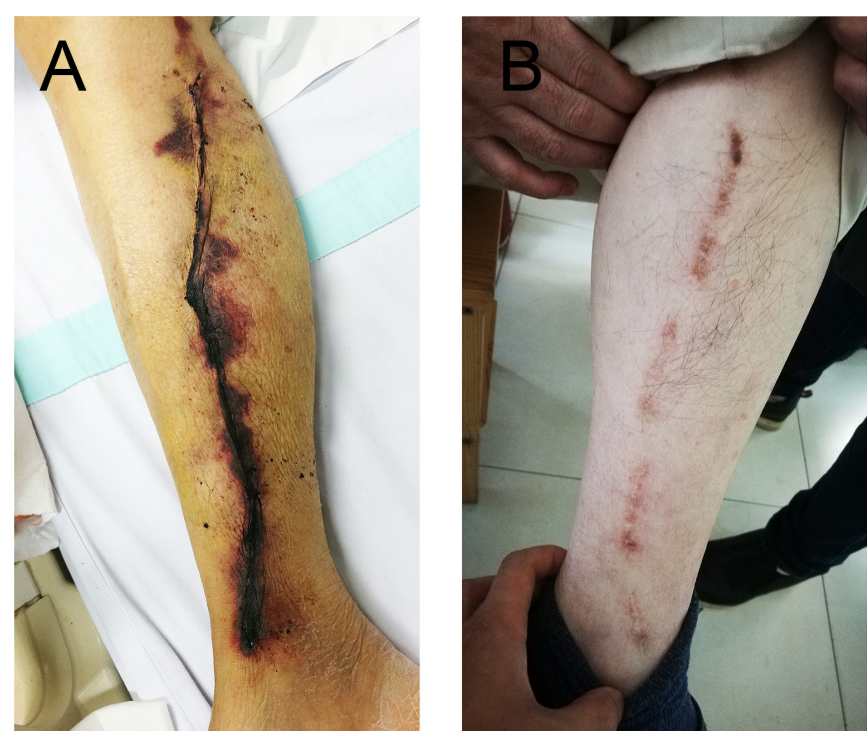

Figure 3. Representative patient with skin necrosis but without infection at the wound margin after surgery in the open NT group (A) and good wound recovery without complications in the bridging/NT group (B) one year post-surgery. 
Table 1. Clinical characteristics of both groups

\begin{tabular}{|c|c|c|c|}
\hline Patients of study & 30 & \multicolumn{2}{|l|}{30} \\
\hline Age at surgery, mean \pm SD & $68.87 \pm 5.53$ & $71.43 \pm 5.09$ & 0.067 \\
\hline Male, n (\%) & $22(73.33)$ & $20(66.67)$ & 0.779 \\
\hline Previous (< 3months) AMI, n (\%) & $2(6.67)$ & $1(3.33)$ & 1.000 \\
\hline Smokers, n (\%) & $15(50.00)$ & $16(53.33)$ & 1.000 \\
\hline Diabetes, n (\%) & $11(36.67)$ & $13(43.33)$ & 0.792 \\
\hline Hyperlipidemia, n (\%) & $8(26.67)$ & $10(33.33)$ & 0.779 \\
\hline Hypertension, n (\%) & $25(83.33)$ & $23(76.67)$ & 0.748 \\
\hline \multicolumn{4}{|l|}{ Medical treatment post surgery } \\
\hline ASA, n (\%) & $30(100.00)$ & $30(100.00)$ & 1.000 \\
\hline ACE-inhibitor, n (\%) & $24(80.00)$ & $26(86.67)$ & 0.731 \\
\hline$\beta$-blockers, n (\%) & $30(100.00)$ & $30(100.00)$ & 1.000 \\
\hline Ca-inhibitor, n (\%) & $14(46.67)$ & $18(60.00)$ & 0.438 \\
\hline Statins, n (\%) & $30(100.00)$ & $30(100.00)$ & 1.000 \\
\hline Ticagrelor, n (\%) & $30(100.00)$ & $30(100.00)$ & 1.000 \\
\hline \multicolumn{4}{|c|}{$\begin{array}{l}\text { There were no statistically significant differences between the two groups. AMI, acute myocardial infarction; ACE, angiotensin-converting enzyme; ASA, ace } \\
\text { salicylic acid; BMI, body mass index; BNP, brain natriuretic peptide; euroSCORE, European System for Cardiac Operative Risk Evaluation }\end{array}$} \\
\hline \multicolumn{4}{|l|}{ Table 2. Intraoperative and postoperative data } \\
\hline Operation time, mean $\pm S D(\min )$ & $266.4 \pm 25.7$ & $266.2 \pm 25.1$ & 0.98 \\
\hline SV graft harvest time $(\min )^{* *}$ & $18.5 \pm 2.6$ & $38.5 \pm 4.9$ & 0.000 \\
\hline \multicolumn{4}{|l|}{ Coronary vessel disease, $\mathrm{n}(\%)$} \\
\hline 2-vessel disease & $6(20.0)$ & $4(13.3)$ & 0.731 \\
\hline 3-vessel disease & $24(80.0)$ & $26(86.7)$ & 0.731 \\
\hline ICU time, mean \pm SD (hours) & $31.7 \pm 10.1$ & $32.5 \pm 7.9$ & 0.722 \\
\hline Satisfaction score* & $6.4 \pm 1.3$ & $7.3 \pm 1.0$ & 0.003 \\
\hline No. of grafts at one-year follow up (patency/total) & $108 / 114$ & $113 / 116$ & 0.331 \\
\hline Atrial fibrillations post-surgery, $\mathrm{n}(\%)$ & $8(26.7)$ & $7(23.3)$ & 1.000 \\
\hline
\end{tabular}

SV, saphenous vein; ICU, intensive care unit; ${ }^{*} P<0.01 ; * * P<0.001$ 
and dicontinuous skin bridging [Ma 2015]. Studies have shown that the long-term patency rate of vein grafts obtained by discontinuous skin bridging is better than that of grafts obtained via laparoscopy [Albäck 2016]. Moreover, these methods cause less wound pain and have a lower infection rate than the traditional full open incisions. In particular, the discontinuous skin bridging method can reduce the incidence of wound infection in patients with diabetes [Black 2002]. In this study, we chose this method, which has low equipment requirements [Khan 2010], and combined it with the NT technique for the first time to obtain SV grafts. Similar to previous results for the discontinuous skin bridging method, our results showed that acquiring vein grafts via discontinuous skin bridging combined with the NT technique could significantly reduce patients' postoperative wound pain and discomfort. At the same time, vein graft length was similar between the two groups. The patency rate in the early postoperative period also was comparable, which did not affect the use of the NT method to obtain the grafts. In terms of the number of postsurgical bleeding branches, our results indicated that the bridging technique did not pose an increased risk of bleeding post-surgery, although the discontinuous skin bridging method posed a greater number of bleeding branches than the open-access technique. However, harvesting time was significantly longer in the discontinuous skin bridging group than in the open NT group. In order to reduce the risk of leg wound complications, such as postsurgical wound swelling [Kim 2017], we left a drainage tube in the leg incision for two or three days. None of the patients involved in the study, including those with diabetes, experienced severe lower limb healing complications. The degree of wound healing and complication rate of the discontinuous skin bridging method were significantly better than those of the full open-access NT group.

Based on the results of our clinical follow up at one year post-surgery, we found that surgeons using the discontinuous skin bridging method combined with the NT method could successfully obtain vein grafts without affecting their earlypatency rate. Although harvesting time was much longer than was the case with the open NT method, the combined discontinuous skin bridging/NT method could significantly reduce complications to the lower extremity and promote patient recovery. At the same time, due to the occlusion of gaps between the skin incisions, partial branches of the vein graft are not sufficiently exposed during separation, which may lead to incomplete or absent branch hemostasis. After the inferior vein grafts are freed and anastomosis is performed with the aortic root, the grafts are expanded by the patient's own blood pressure, with no pressure expansion that can damage graft endothelium. At this point, it is very important to carefully check for branch bleeding again. Due to the emphasis on postoperative branch hemostasis and on repeated examinations during the operations we performed, no case in this study required reopening of the chest for hemostasis due to branch bleeding.

However, the sample size of this study is small, and the patency still needs longer follow up. A multi-center clinical study for such project may be necessary in the future.
CONCLUSION

Obtaining SV grafts via discontinuous skin bridging combined with the NT technique could effectively reduce wound complications and increase satisfaction with leg wound healing, compared with full open NT technique. In addition, the early patency of the grafts was not affected. Extended follow up is necessary to demonstrate the long-term benefits.

\section{REFERENCES}

Albäck A, Saarinen E, Venermo M. 2016. Vein harvesting and techniques for infrainguinal bypass. J Cardiovasc Surg (Torino). 57(2):292-301.

Black EA, Campbell RK, Channon KM, Ratnatunga C, Pillai R. 2002. Minimally invasive vein harvesting significantly reduces pain and wound morbidity. Eur J Cardiothorac Surg. 22(3):381-386.

Deb S, Singh SK, de Souza D, Chu M, Whitlock R, Meyer SR, et al. 2019. SUPERIOR SVG: no touch saphenous harvesting to improve patency following coronary bypass grafting (a multi-Centre randomized control trial, NCT01047449). J Cardiothorac Surg. 14(1):85.

Inaba Y, Yamazaki M, Ohono M, Yamashita K, Izumida H, Hayashi K, et al. 2019. No-touch saphenous vein graft harvesting technique for coronary artery bypass grafting. Gen Thorac Cardiovasc Surg.

Janiec M, Friberg Ö, Thelin S. 2018. Long-term clinical outcomes after coronary artery bypass grafting with pedicled saphenous vein grafts. J Cardiothorac Surg. 13(1):122.

Johansson B, Samano N, Souza D, Bodin L, Filbey D, Mannion JD, et al. 2015. The no-touch vein graft for coronary artery bypass surgery preserves the left ventricular ejection fraction at 16 years postoperatively: long-term data from a longitudinal randomised trial. Open Heart. 2(1):e000204.

Khan UA, Krishnamoorthy B, Najam O, Waterworth P, Fildes JE, Yonan N. 2010. A comparative analysis of saphenous vein conduit harvesting techniques for coronary artery bypass grafting--standard bridging versus the open technique. Interact Cardiovasc Thorac Surg. 10(1):27-31.

Kim YH, Oh HC, Choi JW, Hwang HY, Kim KB. 2017. No-Touch Saphenous Vein Harvesting May Improve Further the Patency of Saphenous Vein Composite Grafts: Early Outcomes and 1-Year Angiographic Results. Ann Thorac Surg. 103(5):1489-1497.

Ma GT, Liu XR, Zhang CJ, Liu JZ, Miao Q, Jiang C, et al. 2015. [Endoscopic Saphenous Vein Harvesting versus Open Vein Harvesting Techniques]. Zhongguo Yi Xue Ke Xue Yuan Xue Bao. 37(4):420-423.

McKavanagh P, Yanagawa B, Zawadowski G, Cheema A. 2017. Management and Prevention of Saphenous Vein Graft Failure: A Review. Cardiol Ther. 6(2):203-223.

Neumann FJ, Sousa-Uva M, Ahlsson A, Alfonso F, Banning AP, Benedetto U, et al. 2019. [2018 ESC/EACTS Guidelines on myocardial revascularization. The Task Force on myocardial revascularization of the European Society of Cardiology (ESC) and European Association for Cardio-Thoracic Surgery (EACTS)]. G Ital Cardiol (Rome). 20(7-8 Suppl 1):1S-61S.

Patel MR, Calhoon JH, Dehmer GJ, Grantham JA, Maddox TM, Maron DJ, et al. 2017. ACC/AATS/AHA/ASE/ASNC/SCAI/SCCT/STS 2017 Appropriate Use Criteria for Coronary Revascularization in Patients With Stable Ischemic Heart Disease: A Report of the American College of Cardiology Appropriate Use Criteria Task Force, American 
Association for Thoracic Surgery, American Heart Association, American Society of Echocardiography, American Society of Nuclear Cardiology, Society for Cardiovascular Angiography and Interventions, Society of Cardiovascular Computed Tomography, and Society of Thoracic Surgeons. J Am Coll Cardiol. 69(17):2212-2241.

Samano N, Dashwood M, Souza D. 2018. No-touch vein grafts and the destiny of venous revascularization in coronary artery bypass grafting-a 25th anniversary perspective. Ann Cardiothorac Surg. 7(5):681-685.

Samano N, Geijer H, Bodin L, Arbeus M, Mannion JD, Dashwood M, et al. 2017. The no-touch saphenous vein graft in elderly coronary bypass patients with multiple comorbidities is a promising conduit to substitute the left internal thoracic artery. J Thorac Cardiovasc Surg. 154(2):457466.e3.

Samano N, Geijer H, Liden M, Fremes S, Bodin L, Souza D. 2015. The no-touch saphenous vein for coronary artery bypass grafting maintains a patency, after 16 years, comparable to the left internal thoracic artery: A randomized trial. J Thorac Cardiovasc Surg. 150(4):880-888.

Samano N, Souza D, Pinheiro BB, Kopjar T, Dashwood M. 2020. Twenty-Five Years of No-Touch Saphenous Vein Harvesting for Coronary Artery Bypass Grafting: Structural Observations and Impact on Graft Performance. Braz J Cardiovasc Surg. 35(1):91-99.

Souza D. 1996. A new no-touch preparation technique. Technical notes. Scand J Thorac Cardiovasc Surg. 30(1):41-44.
Souza DS, Dashwood MR, Tsui JC, Filbey D, Bodin L, Johansson B, et al. 2002. Improved patency in vein grafts harvested with surrounding tissue: results of a randomized study using three harvesting techniques. Ann Thorac Surg. 73(4):1189-1195.

Souza DS, Johansson B, Bojö L, Karlsson R, Geijer H, Filbey D, et al. 2006. Harvesting the saphenous vein with surrounding tissue for CABG provides long-term graft patency comparable to the left internal thoracic artery: results of a randomized longitudinal trial. J Thorac Cardiovasc Surg. 132(2):373-378.

Souza D, Samano N. 2016. Long-term patency versus leg wound healing in coronary artery bypass surgery: Surgical aspects of the no-touch harvesting technique. J Thorac Cardiovasc Surg. 151(1):276.

Wilson AP, Treasure T, Sturridge MF, Grüneberg RN. 1986. A scoring method (ASEPSIS) for postoperative wound infections for use in clinical trials of antibiotic prophylaxis. Lancet. 1(8476):311-313.

Windecker S, Kolh P, Alfonso F, Collet JP, Cremer J, Falk V, et al. 2014. 2014 ESC/EACTS Guidelines on myocardial revascularization: The Task Force on Myocardial Revascularization of the European Society of Cardiology (ESC) and the European Association for Cardio-Thoracic Surgery (EACTS)Developed with the special contribution of the European Association of Percutaneous Cardiovascular Interventions (EAPCI). Eur Heart J. 35(37):2541-2619. 